\title{
An Alternative Forecasting Using Holt-Winter Damped Trend for Soekarno-Hatta Airport Passenger Volume
}

\author{
Arum Handini Primandari
}

Program Studi Statistika, FMIPA, UII

primandari.arum@uii.ac.id

\begin{abstract}
Located in the capital city of Indonesia, Soekarno-Hatta Airport is considered as the main airport. Since there are some aviation companies providing low cost flight, the number people coming and leaving trough this airport has increased. The passenger volume can be considered as seasonal data since it shows increment in particular months, such as long holiday. Knowing in advance the volume of passenger will help the government to improve its service effectively. There is a simple and accurate method for forecasting seasonal data that is called Holt-Winter Exponential Smoothing (HWE). However, HWE always encounters over forecasting problem when it is employed to forecast in some future periods $(m>1)$. In order to solve this problem, we add the damped parameter that will be damping the exponentially growth on HWE. This method called HWE damped trend. We employed the domestic passenger volume data of Soekarno-Hatta Airport from January 2008 till December 2015. This data collected from prior research. As the result, HWE damped trend outperforms traditional HWE on either training data set or testing data.
\end{abstract}

Keywords holt-winter, holt-winter damped trend, trust-region-reflective algorithm

\section{Introduction}

The availability of infrastructure such as transportation function to facilitate either permanent or temporary migration. Basically, transportation is divided into three including land, air, and water transportation. Among the types of transportation, air transportation is the fastest in term of time for travelling. Although there are several issues regarding flight safety, as the technology become more sophisticated the aviation accident
In the early of 90 's, aviation is considered as luxurious transportation service which can be afforded only by high class society. However, in the early of 2000s commercial aviation industries are more arisen providing low cost flight. As the result, flight not only can be afforded by high class society, but also by middlelow society. One of aviation company which jargon is we make people fly, has been proofing its existence providing low cost flight. Because of economical reason risk can be minimalized (BBC, 2014). 
mention above, aircraft became the top choice for long distance travel.

Soekarno-Hatta (Soetta) Airport located in Tangerang, Jakarta is one of Indonesian international airport under Angkasa Pura II, Inc. Since it is located in the capital city of Indonesia, Soetta Airport is considered as main international airport. In attempt to improve its service, the government built terminal 3 ultimate which is launched on June, $15^{\text {th }} 2016$. The reason why the terminal 3 ultimate was built is the high density volume of passengers (Akhir, 2016).

The prediction of passenger volume can be calculated intuitively, for example when Eid or long holiday is coming, the passenger volume will increase significantly. However, the accuracy of this type of prediction is not measurable. Because of this reason, we need to calculate the prediction using scientific method. The accurate forecasting will help the government and related institution to fulfill the need of passenger effectively.

The data of passenger volume can be considered as seasonal data since it shows increment in particular months, such as long holiday. There is a simple method for forecasting seasonal data that is HoltWinter Exponential Smoothing (HWE). Beside its simplicity, HWE is considered having high accuracy (Li, 2013; Taylor, 2012). However, HWE always encounter over forecasting problem when it is employed to forecast in some future periods $(m>1)$. Thus, the prediction value is far from actual data.

The growth factor in HWE trigger the over forecasting problem. In order to solve this problem, we add the damped parameter that will be damping the exponentially growth. This method called HWE damped trend (Hyndman, et. al., 2008; Taylor, 2003).

HWE method consists of some parameters for fitting data. In attempt to obtain the optimum fitting curve, we also need the optimum parameters. The value of its parameters are obtained by using trust-region-reflective algorithm. This algorithm generates gradients of objective function iteratively.

In this paper, passenger volume in Soetta Airport is predicted by employing HWE damped trend. We conduct the research by using trust-region-reflective algorithm in attempt to obtain optimum An Alternative Forecasting Using Holt-Winter Damped Trend for Soekarno-Hatta Airport Passenger Volume 
parameters. As the comparison, the result of HWE damped trend will be compared with the traditional HWE.

\section{Method}

\section{Data}

We used domestic passenger volume data of Soekarno-Hatta Airport from January 2008 till December 2015 (Primandari and Satrio, 2016). Passenger volume is the number of departure and arrival. We split up the data into two different purpose, that are data for building model (training set) and data for forecasting (testing set).

2. Holt-Winter Exponential with Damped Trend

The classic Holt-Winter Exponential Smoothing have three parameters for level $(\alpha)$, growth $(\beta)$, and seasonal $(\gamma)$. Adding the damp parameter $(\phi)$ into HWE to dampening trend, we have the formula of additive HWE method with damped trend express as follow (Hyndman, et al. 2008):

Level :

$\ell_{t}=\alpha\left(y_{t}-s_{t-m}\right)+(1-\alpha)\left(\ell_{t-1}-\phi b_{t-1}\right)$
Growth :

$b_{t}=\beta\left(\ell_{t}-\ell_{t-1}\right)+(1-\beta) \phi b_{t-1}$

Seasonal :

$s_{t}=\gamma\left(y_{t}-\ell_{t-1}-\phi b_{t-1}\right)+(1-\gamma) s_{t-m}$

The prediction formula defines as follow:

Forecast :

$\hat{y}_{t+h}=\ell_{t}+\left(\phi+\phi^{2}+\ldots+\phi^{h}\right) b_{t}+s_{t-m+h}$

Where $y_{t}$ is the actual data at time $t$ and $m$ is the length of seasonality (e.g. the number of months or quarters in a year). The $\ell_{t}, b_{t}, s_{t}$ respectively as level, growth, and season factor at time $t$.

\section{Trust-Region-Reflective Algorithm}

There are several non-linier optimization algorithms to solve optimization problems including newton method, gauss-newton method, and levenberg-marquardt method. The trustregion optimization method in combination with the interior reflective Newton algorithm can be a powerful approach to solve constrained non-linear minimization problems.

The trust-region method approximates an objective function $f(x)$ with quadratic function $q(s)$, which is a 
reflection of function $f(x)$ in a neighborhood $N$ around the current point $x$, in which $x$ is a constrain vector. The neighborhood $N$ is called trust-region. Mathematically, the trust-region-reflective method sub problem is stated as follow (Le and Fatahi, 2016):

$\min _{s} q(s)=\min _{s}\left(\frac{1}{2} s^{T} H s+s^{T} g\right) \quad$ such that $\|D s\| \leq \Delta$,

where $g$ is the gradient of function $f(x)$ for current $x, H$ is a symmetric matrix of second derivatives (Hessian matrix), $D$ is a diagonal scaling matrix, $\Delta$ is the trustregion radius $>0$, and $\|\cdot\|$ is the second norm.

A trial step $s$ is computed by minimalizing the area $N$ in equation (2). If $f(x+s)<f(x)$, the current point $x$ is updated to be $x+s$, otherwise the vector $\mathrm{x}$ remains unchanged and the area $\mathrm{N}$ is shrunk into next step.

\section{Error Measurement}

Error is the difference between predicted value and actual value. The error measurements are used to measure the accuracy of forecasting. We employ two type of measurements that are the absolute error and relative error. The absolute error is the maximum error. We use RMSE (Root Mean Squared Error) as absolute error measurement given as follow ( $\mathrm{Li}$ 2013):

$$
R M S E=\sqrt{\frac{1}{n} \sum_{t=1}^{n}\left(y_{t}-\hat{y}_{t}\right)^{2}} .
$$

Where $n$ is the amount of data, $y_{t}$ is the actual data at time $t$ and $\hat{y}_{t}$ is the prediction at time $t$. The relative error compares the error by actual data. We use MAPE (Mean Absolute Percentage Error) to measure relative error.

$$
\text { MAPE }=\frac{1}{n} \sum_{i=1}^{n} \frac{\left|y_{t}-\hat{y}_{t}\right|}{y_{t}} \times 100 \%,
$$

where $|\cdot|$ is the absolute value of its argument.

\section{Numerical Result}

The number of arriving passengers in Soekarno Hatta Airport from January 2008 to December 2015 fluctuated around 1 million people and so did the number of departing passengers. The average of arrival is 1.585 .168 people, while the average of departure is 1.435 .262 people. According to this average, people tend to 
come to the capital. Below is the graph of arrival and departure.

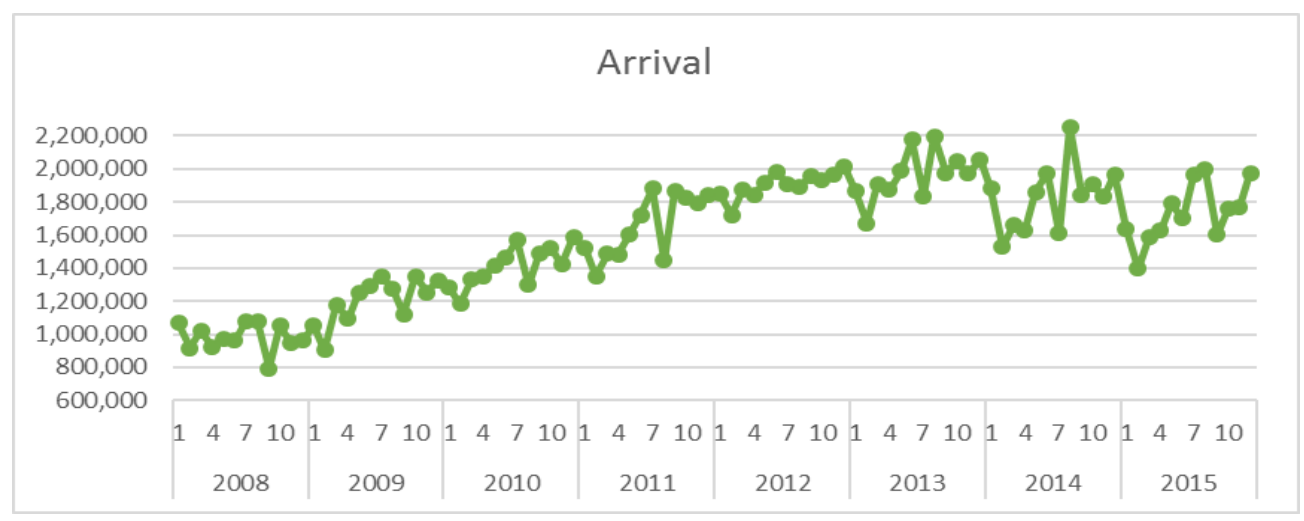

(a)

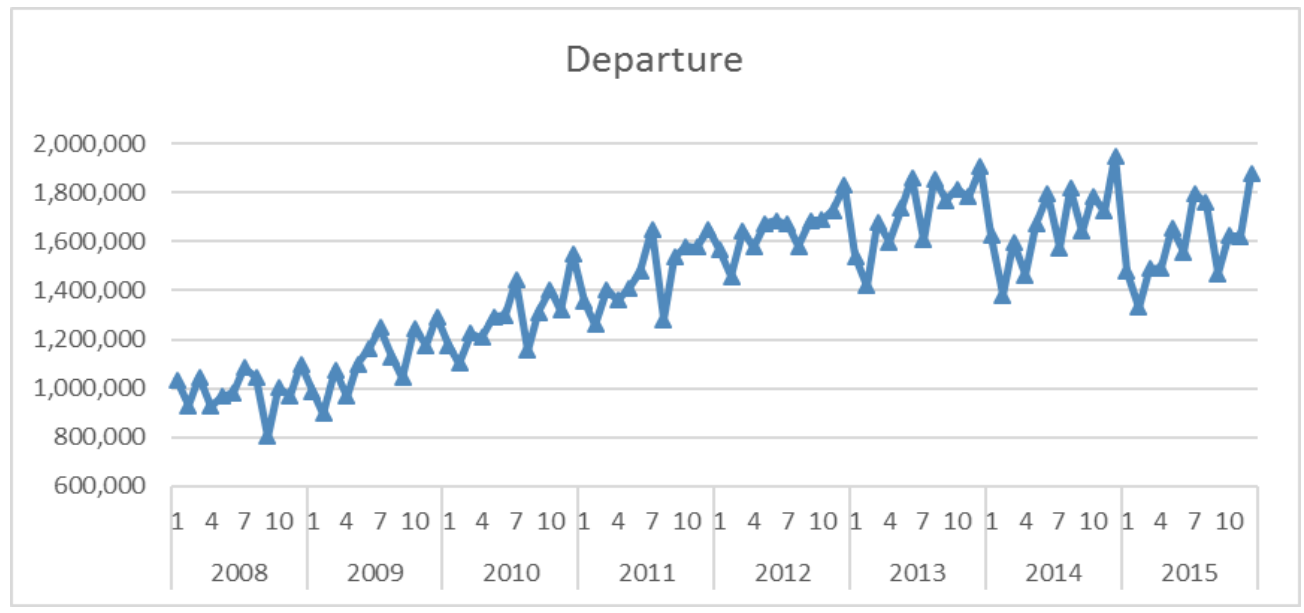

(b)

Figure 1. (a) The Number of Arrival; (b) The Number of Departure of Soetta Airport from January 2008 to December 2015

Even though the number people coming to the capital is greater than the people who is leaving, but the both are proportional. It can be seen from the graph that arrival and departure barely have the same pattern.
The red marks on the graph are the month in which Eid was held. Because of about $85 \%$ Indonesia citizen are muslims (Republika, 2016), once in every year there are massive movement into hometown to celebrate Eid called mudik. But, according to the graph, this mudik do not always

An Alternative Forecasting Using Holt-Winter Damped Trend for Soekarno-Hatta Airport Passenger Volume 
increasing the volume of flight occupant. Thus, Eid do not affect the seasonal.
The flight occupant during the observed years summed up monthly presented in Fig.3.

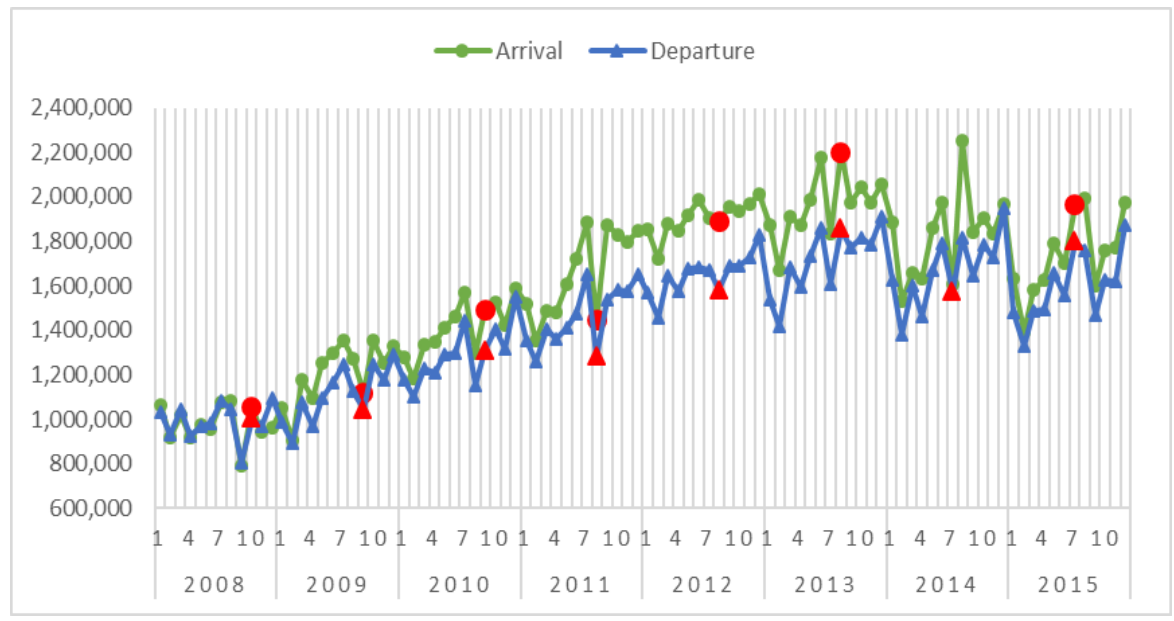

Figure 2. The Comparison of Number of Arrival and Departure

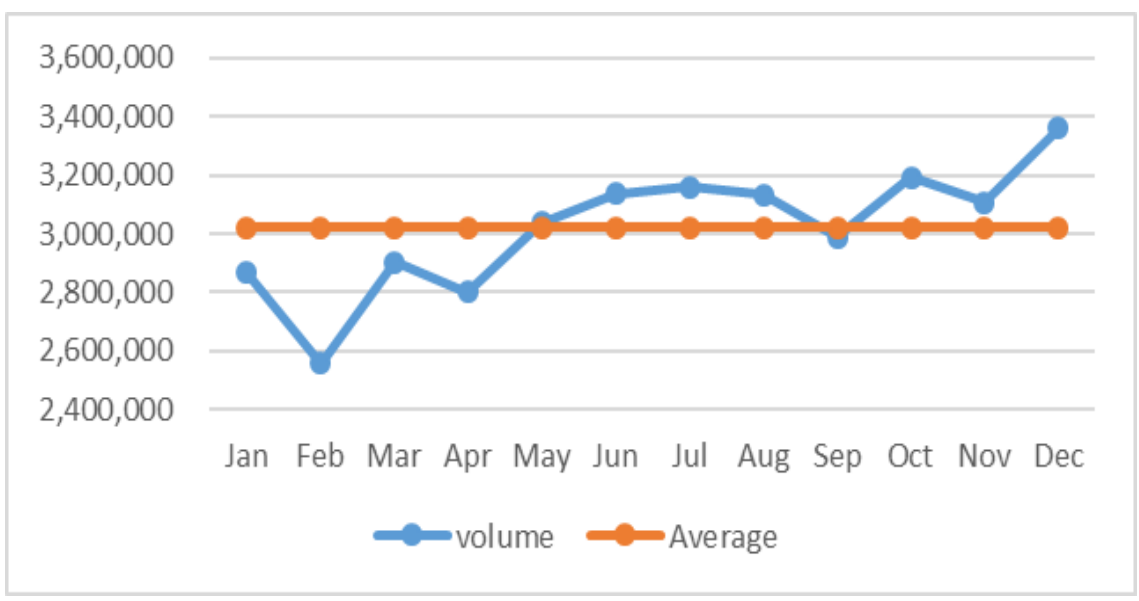

Figure 3. Passenger Monthly Recapitulation

According to Fig.3., the lowest number of passengers is on February, whereas the highest is on December. Meanwhile, the passenger volume of others months fluctuates around the average. This figure also explains that from January 2008 to December 2015, February become the month with low volume of passenger on average. Thus we can clearly see the seasonal pattern 
We work on passenger volume data from January 2008 to July 2015 to obtain fitting curve of HWE damped trend. The optimum parameters obtained from trust- $\alpha=0,9093 ; \beta=0,4888 ; \quad \gamma=0,118, \quad$ and $\phi=0,8284$. The separately graph of level, growth, and seasonal pattern are presented below.

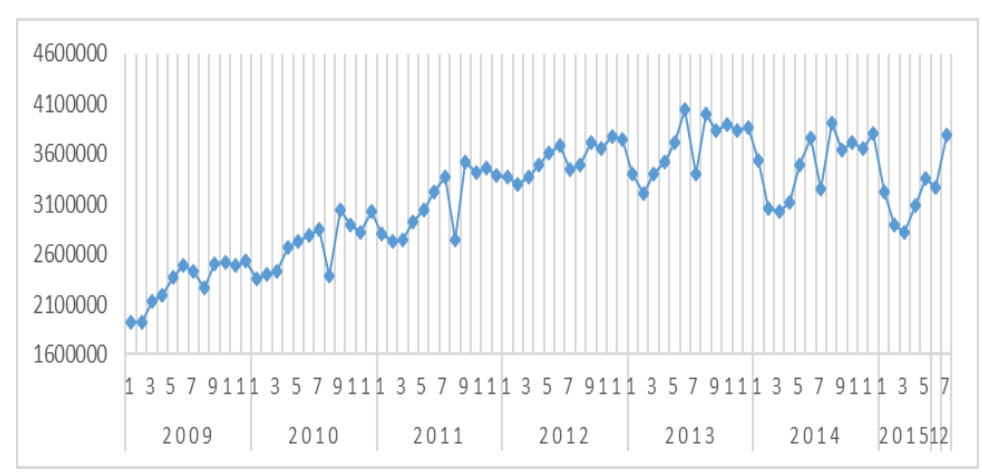

(a)

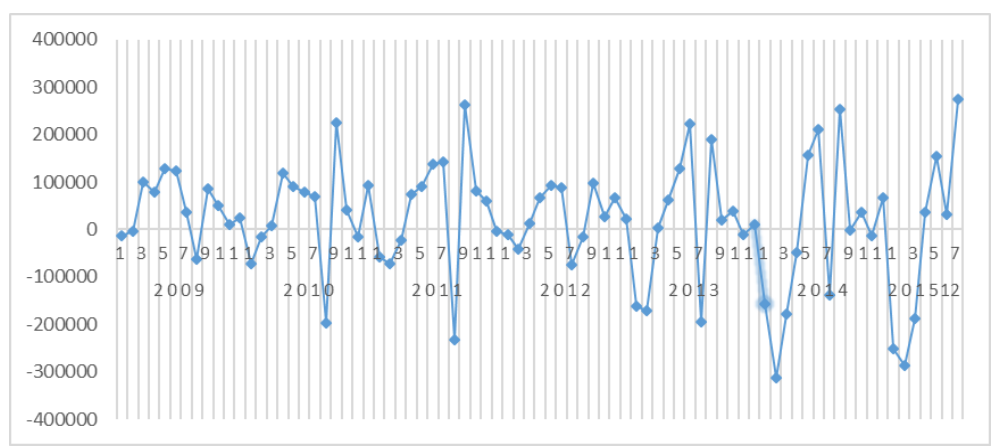

(b)

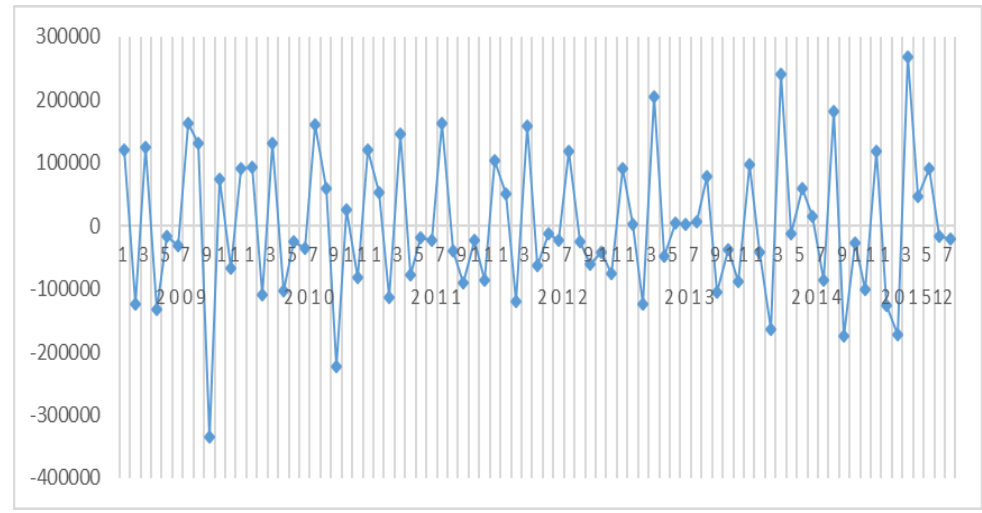

(c)

Figure 4. The Level, Growth, and Seasonal Factors on Training Data 


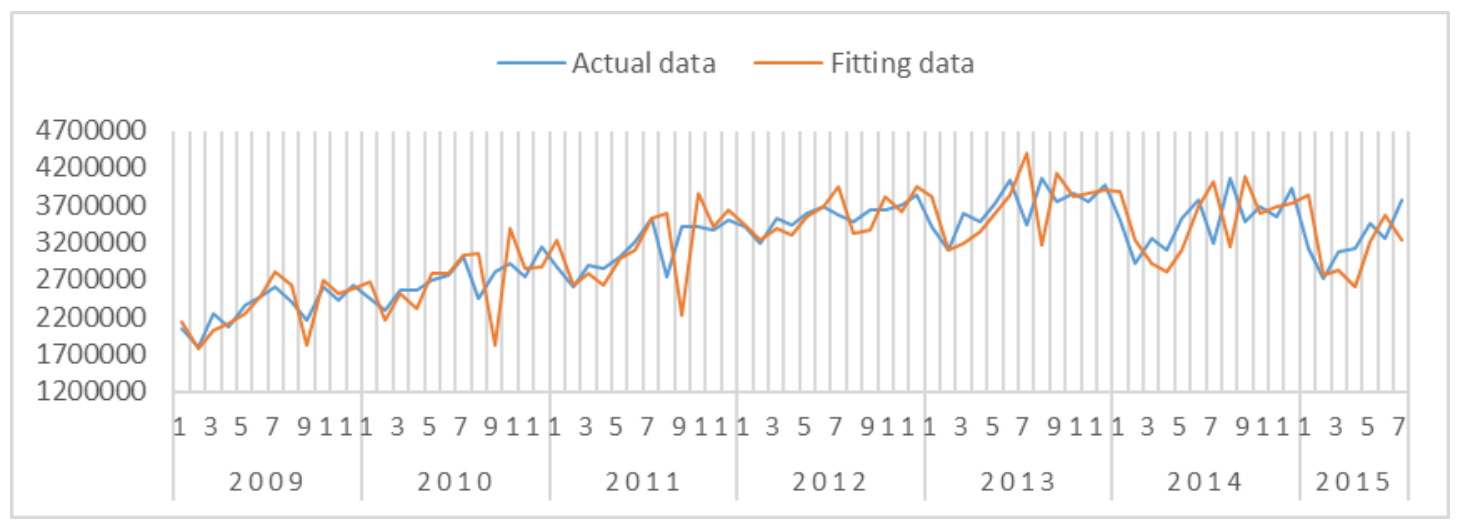

Figure 5. The Comparison of Fitting Data with Actual Data

Based on Fig.5. the HWE damped trend performs well enough for fitting the actual data, even though it cannot follow every points perfectly. The comparison between HWE damped trend and traditional HWE is given below.

Table 1. Training Data Performance Comparison

\begin{tabular}{|c|l|r|r|}
\hline \multirow{2}{*}{ No } & \multirow{2}{*}{ Item } & \multicolumn{2}{|c|}{ Method } \\
\cline { 3 - 4 } & & HWE & $\begin{array}{c}\text { HWE } \\
\text { Damped } \\
\text { Trend }\end{array}$ \\
\hline 1. & Alpha $(\alpha)$ & 0,9196 & 0,9093 \\
\hline 2. & Beta $(\beta)$ & 0,5250 & 0,4888 \\
\hline 3. & Gamma $(\gamma)$ & 0,1091 & 0,1180 \\
\hline 4. & Phi $(\phi)$ & - & 0,8284 \\
\hline 5. & RMSE & $374.600,65$ & $351.904,60$ \\
\hline 6. & MAPE & $8,28 \%$ & $7,87 \%$ \\
\hline & \multicolumn{2}{|c|}{ According } & to both RMSE and
\end{tabular}

MAPE, we can see that HWE damped trend outperform traditional HWE.
We use passenger volume data from August to December 2015 for checking the forecasting performance obtained in fitting data.

Table 2. Forecasting Comparison of Testing Data

\begin{tabular}{|c|l|c|c|c|}
\hline \multirow{2}{*}{ No } & \multirow{2}{*}{ Month } & $\begin{array}{c}\text { Actual } \\
\text { Data }\end{array}$ & HWE & $\begin{array}{c}\text { HWE } \\
\text { Damped } \\
\text { Trend }\end{array}$ \\
\hline 1 & Aug & 3755975 & 4265057 & 4208792 \\
\hline 2 & Sept & 3069917 & 4185218 & 4041510 \\
\hline 3 & Oct & 3383565 & 4613279 & 4345361 \\
\hline 4 & Nov & 3390041 & 4827760 & 3658842 \\
\hline 5 & Dec & 3851713 & 5330451 & 3805369 \\
\hline
\end{tabular}

According Table 2., the forecast values of HWE always increase exponentially trough the periods. Therefore, its value is far from the actual value. On the other way, HWE damped trend prediction values still follow the trend of the actual values, either downward or upward. Thus,

An Alternative Forecasting Using Holt-Winter Damped Trend for Soekarno-Hatta Airport Passenger Volume 
the forecasting value of HWE damped trend is more plausible than traditional HWE.
The comparison is shown on the graph in Fig. 6.

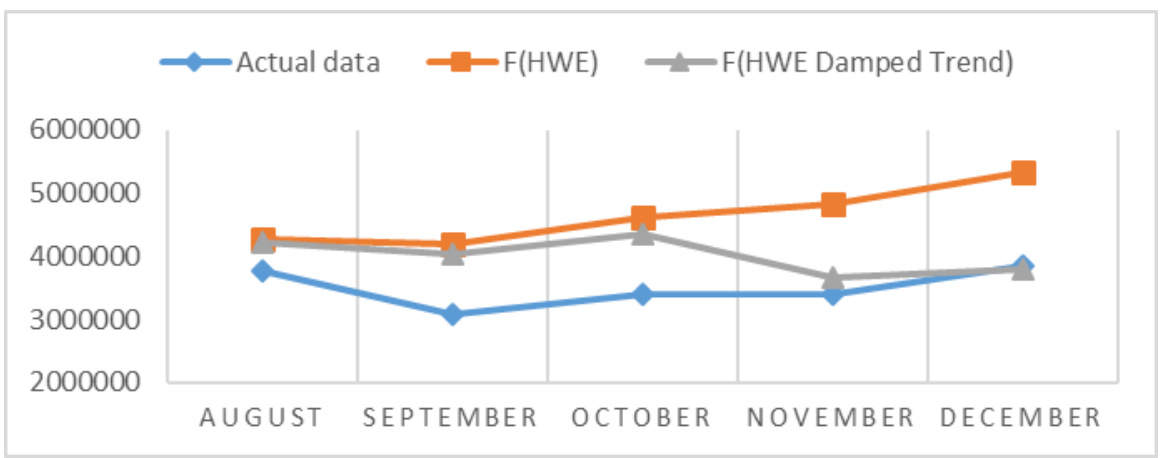

Figure 6. The Forecasting Performance Comparison

On November, we can clearly see that

HWE forecasting continue to rise, whereas the HWE damped trend slide down to actual data.

\section{Conclusion}

The HWE with damped trend outperformed traditional HWE both training and testing data set. Although, the optimum parameters of HWE damped trend and HWE did not show much difference, the value of RMSE and MAPE of HWE damped trend are significantly smaller than HWE. Moreover, the testing data set graph indicated that HWE forecasting do not encounter over forecasting. So that, adding the damped parameter in Holt-Winter Exponential Smoothing was successfully damping the trend to rise exponentially.
Thus the damped parameter reduces the error measurement of testing data forecasting. We can employ HWE damped trend to predict the next passenger volume.

\section{References}

Akhir, D. J., HOT BISNIS: Terminal 3 Ultimate, Bandara Modern di Indonesia, Retrieved from Okezone:http://economy.okezone.co $\mathrm{m} / \mathrm{read} / 2016 / 06 / 10 / 320 / 1411471 / \mathrm{ho}$ t-bisnis-terminal-3-ultimatebandara-modern-di-indonesia. Diakses tanggal Juni 20, 2016.

BBC, AirAsia QZ8501: Does bad weather cause plane crashes?, Retrieved from $\mathrm{BBC}$ : http://www.bbc.com/news/world30631968. Diakses tangal 30 Desember, 2014.

Hyndman, R. J., et. al., 2008, Forecasting with Exponential Smoothing: The An Alternative Forecasting Using Holt-Winter Damped Trend for Soekarno-Hatta Airport Passenger Volume 
State Approach, Deblik, Berlin, Germany: Springer.

Le, T. M., \& Fatahi, B., 2016, Trust-Region Reflective Optimisation to Obtain Soil Visco-Plastic Properties, International Journal for ComputerAided Engineering and Software, 33(2), 410-442.

Li, X., 2013, Comparison and Analysis between Holt Exponential Smoothing and Brown Exponential Smoothing Used for Freight Turnover Forecast, Proceedings Third International Conference on Intelligent System Design and Engineering Applications (ISDEA) 2013, ISBN: 978-0-7695-4923-1, 453-456. Held in Hongkong China by IEEE.

Primandari, A. H., \& Satrio, A. P., 2016, Grey Double Eksponential Smoothing dengan LevenbergMarquardt untuk Peramalan Volume Penumpang di Bandara Soekarno Hatta, Yogyakarta: Laporan Penelitian Tidak Dipublikasi.

Republika, 2016, Januari 9, Persentase Umat Islam di Indonesia Jadi 85 Persen, Retrieved from Republika News:

https://m.republika.co.id/berita/nasi onal/umum. Diakses 9 Januari, 2016

Taylor, J. W., 2003, The Exponential Smoothing with a Damped Multiplicative Trend, International
Journal of Forecasting, 19, 715725.

Taylor, J. W., 2012, Density Forecasting on Intraday Call Center Arrivals Using Models Based on Exponential Smoothing, Management Science, 53(3), 534-549. 